\title{
The Classification of Accidental Situations' Scenarios on Hydropower Plants
}

\author{
Olga Skvortsova ${ }^{1}$, Anastasiia Dashkina $^{1, a}$, Ekaterina Petrovskaia ${ }^{1}$, Vitaly Terleev ${ }^{1}$, \\ Aleksandr Nikonorov ${ }^{1}$, Vladimir Badenko ${ }^{1}$, Yulia Volkova ${ }^{1}$ and Sergey Pavlov ${ }^{1}$ \\ ${ }^{1}$ Peter the Great St.Petersburg Polytechnic University, Polytechnicheskaya, 29, St. Petersburg 195251, Russia
}

\begin{abstract}
The collapse of hydropower plant could lead to significant financial, social and environmental damages. Accordingly the issue of safety and reliability is one of major problems of designing, maintenance and operation. The proposed solution consists in evaluation of implementation frequency of emergencies scenario, which can be defined by suggested classification of accidental situations' scenarios based on systems analysis to implement incidents on hydropower plants. Emergency scenarios on hydropower plants were proposed to classify by three criteria: the cause, place and character
\end{abstract}

\section{Introduction}

The issue of reliability and safety of hydraulic structures is paid much attention both in Russia and abroad. Particularly this problem became acute because of the biggest hydro accident in the history of modern Russia, which took place 17 August 2009 on Sayano-Shushenskaya Hydroelectric Power Station.

At present, the main task for the energy is to ensure the safe and reliable operation of hydraulic structures), hydropower plants (complex and unique objects), the collapse of which could lead to significant financial, social and environmental damages [1-9].

This task includes the development by power plants of "Declaration of safety of hydraulic structures". In drawing up the declarations of safety, as stated above, the law requires a quantitative assessment of the level of safety of hydraulic structures. We know that measure of security is a level of risk:

$$
R=P \cdot Y,
$$

where $P$ - the probability of an emergency at the facility, and $Y$ - the value of the damage caused as a result of an emergency. Therefore, for assessing the safety of the facility, the actual task is determining the scenarios of possible emergency situations on the specific hydraulic structures and determination of the probability of their realization.

A review of literature on the issues of the safety assessment hydropower plant, and determining the number and probability of potential accidents at these sites, can be used to allocate the next methods to resolve it:

- The deterministic method based on the calculation method of limiting states [10-12].

${ }^{a}$ Corresponding author: dashkinanastia@mail.ru 
- A probabilistic approach. It is based on a deterministic method of limiting states, but taking into account the random variation, as the parameters of materials and possible impacts and loads [13-14].

- The method of statistical analysis. The basis of this method is the determination of the number of accidents to implement in relation to the number of objects and considered their life [15$17,7]$.

- The expert method. It is based on the knowledge and experience of experts to assess the risk of emergency on hydropower plants [18-22].

\section{Materials and methods}

From our point of view, the closest to the problem of determining the number and the probability of accident scenarios on a particular object a method, based on a complex three-dimensional association, to carry out statistical analysis of actual accidents and expert assessment with use of the general laws of a particular object. To adapt the method of expert assessment to the definition of the probability of the causes of accidents at a particular site needs to develop scenarios of possible emergencies [23-26].

All possible scenarios of hydroelectric facilities on emergency situations in the future are treated as a single set (system). Representing the whole set of particular groups, i.e. classification, is necessary to select the features that would be independent and common to $\rho\left(X_{j}^{1}=\right.$ const $; X_{j}^{2}=$ const $\left.; X_{j}^{3}\right)=\frac{N\left(X_{j}^{1}=\text { const } X_{j}^{2}=\text { const } ; X^{3} j^{3}\right)}{N_{0}}$ all scenarios analyzable set. Then, the principle is the principle of allocation of classification groups of scenarios with the same values of these attributes:

$$
X^{1}, X^{2}, \ldots, X^{i}, \ldots, X^{n} .
$$

Signs of the scenarios under consideration may be quantitative or qualitative (i.e. their value can be expressed either a number or a set of quality values). Furthermore, they may be discrete or continuous values. An important property is the sign and the range of their possible values.

Then, if the sign of $X^{i}$ is characterized like the discrete value, it receives a set of discrete values:

$$
X_{1}^{i}, X_{2}^{i}, \ldots, X_{j^{i}}^{i}, \ldots, X_{j_{\max }^{i}}^{i},
$$

where $J_{\max }^{i}$ specifies the maximum value $X_{j^{i}}^{i}$ attribute and therefore the range of change of $X^{i}$ attribute. And $X_{j}^{i}$ may be a number, if the attribute belongs to quantitative estimation, or it could be qualitative parameter on an attribute scale if it is quality.

Based on the above, the whole set of scenarios can be divided into separate groups, all emergencies within these groups are characterized by the same value of the parameters of classification, i.e.

$$
X_{j}^{i}=\operatorname{const}\left(i=1, ., n, \text { where } j^{i}=1, \ldots, j_{\max }^{i}\right) .
$$




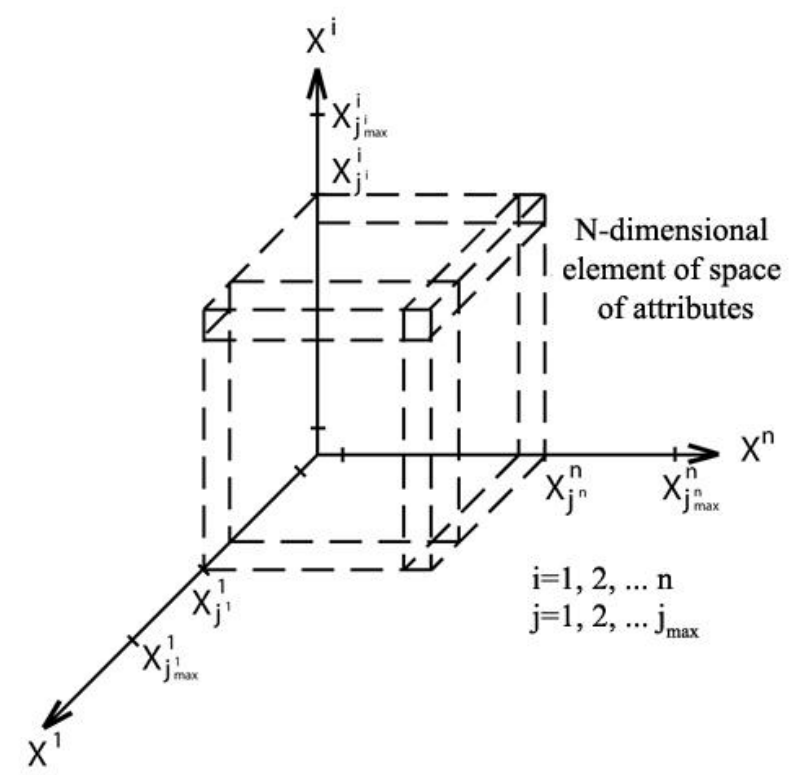

Figure 1. Discrete n-dimensional space of emergencies attributes.

Setting the range of change parameters $\left(\mathrm{J}_{\mathrm{i}}=1, \ldots, J_{\text {imax }}\right.$, for $\left.i=1, \ldots, \mathrm{n}\right)$ allows you to calculate the volume $V_{n}$ (number of elements) all n- dimensional space of attributes:

$$
V_{n}=J_{\max }^{1}, J_{\max }^{2}, \ldots, J_{\max }^{i}, \ldots, J_{\max }^{n}=\prod_{i=1}^{n} J_{\max }^{i} .
$$

The introduction of the concept of space of attributes allows determining the coordinates of each element of this space: $\left(\mathrm{X}_{j}^{1}, \ldots, X_{j}{ }_{j} i, \ldots, X_{j}{ }_{j}{ }^{n}\right)$ and thereby determine the position of any class of accident scenarios. The latter allows implementing the mathematical formalization of operations with such phenomena as the development of processes of accidents. Introduce the function for the discrete space of attributes:

$$
P_{0}\left(X_{j^{1}}^{1}, \ldots X_{j^{\prime \prime}}^{i^{\prime \prime}}, \ldots X_{j^{n}}^{n}\right) \text {. }
$$

This determines the probability of implementation of groups of scenarios of accidental situations, belongs to an element of the space of coordinates $X_{j}^{1}{ }_{j}, \ldots, X_{j}^{i}{ }_{j}, \ldots, X^{n}{ }_{j}{ }^{n}$. Then, knowing the value of $n$ and $J_{\max }^{i "}$, we can estimate the probability of the realization of all accident scenarios on hydropower plants. Obviously, the implementation of accident scenario depends on so many factors, that any attempt to obtain an analytic expression for the function $P_{0}$ is not feasible at the moment.

Therefore, the only possible solution of the problem is the way of collecting data on the practice of accidental situations, their classification by attributes $X^{i}$ and calculating the number of implementations belongs to the elements of PP (the path of experienced tabulation of the function $\left.P_{0}\right)$.

Let $N\left(X_{j}^{1}{ }^{1}, \ldots X_{j}^{i}, \ldots X_{j^{n}}^{n}\right)$ be the number of accident scenarios with attributes $X_{j^{1}}^{1}, \ldots X_{j^{i}}^{i}, \ldots X_{j^{n}}^{n}$ belong to the PP element with same coordinates. Then the relation: 


$$
\rho=\frac{N\left(X_{j}^{1}{ }^{1}, \ldots, X_{j}^{i}{ }^{i}{ }, \ldots, X^{n}{ }_{j}{ }^{n}\right.}{N_{0}},
$$

shows the relative frequency implementations of process with coordinates $\left(X_{j}^{1}, \ldots, X_{j^{i}}^{i}, \ldots, X_{j^{n}}^{n}\right)$ to the total number $N_{o}$. of considered accidental scenarios. Obviously, the value of the function $\rho$ will strive to values of function $P_{0}\left(X_{j^{1}}^{1}, \ldots, X_{j^{i}}^{i}, \ldots, X_{j^{n}}^{n}\right)$ by increasing the number $N_{o}$ :

$$
P_{0}\left(X_{j 1}^{1}, \ldots, X_{j^{i}}^{i}, \ldots, X_{j^{n}}^{n}\right) \Rightarrow \lim _{N \Rightarrow \infty} \frac{N\left(X_{j^{1}}^{1}, \ldots, X_{j^{i}}, \ldots, X_{j^{n}}\right)}{N_{0}} .
$$

\section{Results and Discussion}

Thus, to solve the problem of estimating the frequency of implementation of accident scenarios it is necessary to:

Identify the main attributes, which will define the classification of the scenarios of processes of accidental situations; determine the number of the scenario of accident situation that belongs to one or another element of space of attributes (practically, it is an empirical tabulation of function $P_{0}$ ).

Since the considered information from data bank is the expert (mixed) mode (requires nonalgorithmic knowledge), then for analysis it is extremely important to have an emergency circuit, as well as photographs of the failure or accidents and their consequences. The analysis of the distribution of emergency situations, depending on their scene, mode, etc. is important for designers and operating personnel sector. Distribution of accidents according to the main reasons for their occurrence is shown in the corresponding histogram.

From the histogram it can be seen that the main reasons are faults in design $(17 \%)$, river floods $(12 \%)$, filtering $(9 \%)$, defects in construction and equipment $(6 \%)$. Therefore, it is extremely important to raise the quality of the design and provide additional measures of precaution against floods and filtering $[27,28]$. These studies are, of course, give a far from complete picture, however, it is possible to objectively identify any critical points in the design, construction and exploitation of hydroelectric power plants.

To carry out the systematic analysis of real accidents to identify common, independent marks of classification three following attributes can be selected:

1) $X^{i=1}: X^{1}$ — cause of accident $(i=1)$;

2) $X^{i=2}: X^{2}$ - accident scene $(i=2)$;

3) $X^{i=3}: X^{3}$ - accident mode $(i=3)$.

Thus, the system of accidental scenarios on the hydroelectric power plants is proposed to be classified according to three criteria: the cause, scene and mode. The numbers $J_{\max }^{1}, J_{\max }^{2}$ and $J_{\max }^{3}$ at the figure define the number of values taken by the attributes $X^{1}, X^{2}, X^{3}$. In accordance with the classification selected features, scenarios of emergency situations of the entire system will be described by the three-dimensional discrete elements, orthogonal space (see. figure 1). The total amount of attribute's space, containing all the possible scenarios of real emergencies, according to the formula (6) is equal to $V_{3}=J_{\max }^{1} \cdot J_{\max }^{2} \cdot J_{\max }^{3}=22 \cdot 17 \cdot 19=7106$. 


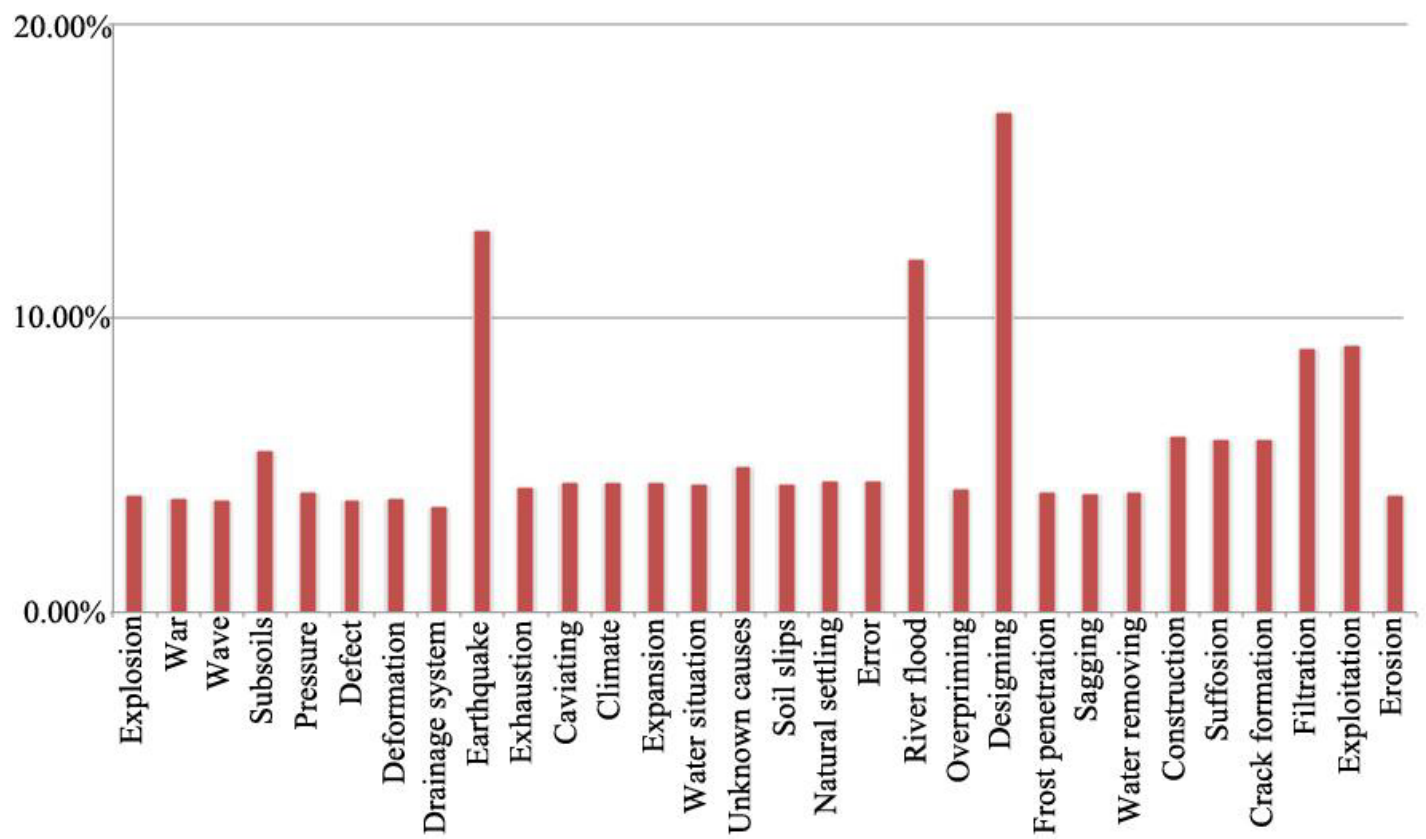

Figure 2. Histogram distribution of accidental situations on hydropower plants depending on the cause of the accident.

The distribution function of the probability of accidents on the three-dimensional feature space elements will look like $P_{0}\left(X_{j^{1}}^{1}, X_{j^{2}}^{2}, X_{j^{3}}^{3}\right)$, where $X_{j^{-1}}^{1}, X_{j^{-2}}^{2}, X_{j^{-3}}^{3}-$ the coordinates, including all the scenarios of accidents with these values of classification.

$$
\rho\left(X_{j 1}^{1}, X_{j^{2}}^{2}, X_{j 3}^{3}\right)=\frac{N\left(X_{j 1}^{1}, X_{j}^{2}, X_{j}^{3}\right)}{N_{0}} .
$$

Here $N\left(X_{j}^{1}{ }_{1}, X_{j}^{2}{ }^{2}, X_{j}^{3}\right)$ - the number of actual ongoing accident scenarios with the attributes: $X_{j^{1}}^{1}, X_{j^{2}}^{2}, X_{j^{3}}^{3} ; N_{0}$ - the total number of accidental scenarios; $\rho\left(X_{j}^{1}, X_{j}^{2}{ }_{2}, X_{j}^{3}{ }_{3}\right)-$ the relative number (frequency) of unrealized accidental scenarios with the attributes: $X_{j^{1}}^{1}, X_{j^{2}}^{2}, X_{j}^{3}$.

Numerical values of $\mathrm{N}$ and $N_{0}$ are determined by analyzing a database of real emergencies, "GTA". The algorithm of this calculation is represented by the following operations.

- All cases with one of the characteristic values $X^{1}$ (cause): $X_{j}^{1}$ are selected.

- From the resulting array at paragraph 1 accident scenarios all the processes with the value $X_{j^{2}}^{2}$ attribute ${ }^{2}$ (the accident site) are selected.

- From the array of implementation of accident scenarios, received from operations carried out in paragraph 2, with the help of an automated data system distribution of processes emergencies histogram can be built on the basis of $X^{3}$ (mode of the accident). The result is a number of emergency scenarios implemented in each element of the column $X_{j^{1}}^{1}=$ const; $X_{j^{2}}^{2}=$ const at the space of attributes distributed by characteristic values of attribute $X^{3}: X_{j 3}^{3}\left(J^{3}=1,2, \ldots, J_{\max }^{3}\right)$, which means that numbers $N\left(X_{j^{1}}^{1}=\right.$ const $; X_{j^{2}}^{2}=$ const $\left.; X_{j^{3}}^{3}\right)$ are obtained. 
- By dividing the numbers $N$, obtained in step 3 by the total number of pending emergency situations $N_{0}$ can be founded the desired frequency of implementations of processes emergencies:

$$
\rho\left(X_{j^{1}}^{1}=\text { const } X_{j^{2}}^{2}=\text { const } ; X_{j^{3}}^{3}\right)=\frac{N\left(X_{j^{1}}^{1}=\text { const } ; X_{j^{2}}^{2}=\text { const } ; X_{j^{3}}^{3}\right)}{N_{0}},
$$

i.e. distribution of processes' mode is taking place at scene $X_{j^{2}}^{2}=$ const. due to the cause $X_{j}^{1}=$ const.

- To get the frequency $\rho$ distribution of the character and place of accidents that have occurred due to $X^{1}{ }_{j}=$ const it is necessary to perform operation of paragraphs 3 and 4 of this algorithm cyclically for all characteristic values $X^{2}: X_{j^{2}}^{2}\left(j^{2}=1,2, \ldots, j_{\max }^{2}\right)$.

- For the implementation of the processes of frequencies emergencies around the threedimensional space of attributes it is necessary to cyclically repeat steps $1-5$ of the algorithm for all the characteristic values of $X^{1}: X_{j^{1}}^{1}\left(j^{1}=1,2, \ldots, j_{\text {max }}^{1}\right)$.

The result of this algorithm gives a list of really existent classes of accident scenarios and the frequency of their implementation. The algorithm described above allows receiving function $\rho\left(X_{j}^{1}{ }_{j}, X_{j}^{2}{ }^{2}, X_{j}^{3}\right)$ in three-dimensional space of attributes, which defines as the class of scenarios of emergency situations as the frequency of their implementation [29-34].

The function $\rho\left(X_{j}^{1}{ }_{j}, X_{j}^{2}, X_{j}^{3}{ }^{3}\right)$ determines general regularities of processes of accidental situation's scenario development on hydroelectric power stations. But, obviously, it can't take in account the individual distinctive features of each particular object.

\section{Conclusions}

So here is the question of how to complement existing information about typical patterns with data that take into account the specific features of the object. It is impossible to reveal the statistical regularities of emergencies at a particular object, as if it has a large number of accidents it has to be closed. Therefore, the only way to obtain the necessary baseline information is to use the experience and knowledge of adepts, treated by the expert evaluation method.

\section{References}

1. G.T. Aronica, A. Candela, P. Fabio, M. Santoro, Phys. Chem. Earth, 42-44, 119-129 (2012)

2. O.S. Skvortsova, Proceedings of the Chetvertaya Sankt-Peterburgskaya assambleya molodykh uchenykh i specialistov, (1999) (rus)

3. V. Chechevichkin, N. Vatin, AMM, 641-642, 409-415 (2014)

4. A Bayburin, Procedia Eng. 117, 73-79 (2015)

5. A. Nikonorov, S. Pavlov, V. Terleev, N. Arefiev, V. Badenko, Y. Volkova, Procedia Eng. 117, 258-263 (2015)

6. V. Badenko, V. Terleev, A. Topaj, AMM, 635-637, 1688-1691 (2014)

7. S. Medvedev, A. Topaj, V. Badenko, V. Terleev, IFIP AICT, 448, 252-261 (2015)

8. A. Makarov, A. Mihailova, N. Arefiev, S. Pavlov, T. Chashchina, V. Terleev, V. Badenko, Procedia Eng. 117, 225-231 (2015)

9. N. Arefiev, V. Garmanov, V. Bogdanov, Y. Ryabov, V. Terleev, V. Badenko, Procedia Eng. 117, 26-31 (2015)

10. L. You, C. Li, X. Min, T. Xiaolei, Procedia Eng. 28, 382-38 (2012)

11. H. Apel, A.H. Thieken, B. Merz, G. Blöschl, Nat. Hazards Earth Syst. Sci. 4, 295-308 (2004) 
12. M. Balzannikov, Procedia Eng. 111, 65-71 (2015)]

13. Robin Fell, Simposium in Stokholm, June 5-7, 567-576 (1996)

14. H. Apel, A.H. Thieken, B. Merz, G. Blöschl, Nat. Hazards Earth Syst. Sci. 38, 79-100 (2006)

15. D.N.D. Hartford, International Journal on Hydropower and Dams 18, 66-70 (2011)

16. N.V. Arefiev, V.L. Badenko, G.K. Osipov, Power Technology and Engineering 32, 660-663 (1998)

17. S. Ahmad, S. Simonovic, J COMPUT CIVIL ENG. 190-198 (2000)

18. O.S. Skvortsova, N.V. Arefiev, Proceedings of the XXIX nedelya nauki SPbGTU (2001) (rus)

19. O.S. Skvortsova, Aquaterra Sbornik materialov konferencii (2000) (rus)

20. N. Arefiev, V Terleev, V. Badenko, Procedia Eng. 117, 39-44 (2015)

21. N. Arefiev, V. Badenko, A. Nikonorov, V. Terleev, Y. Volkova, Procedia Eng. 117, 20-25 (2015)

22. Y.G. Motovilov, V.I. Danilov-Danilyan, E.V. Dod, A.S. Kalugin, Water Resources 42, 580-593 (2015)

23. L. Muravyeva, N. Vatin, AMM, 635-637, 468-471 (2014)

24. L. Muravyeva, N. Vatin, AMM, 633-634, 1042-1046 (2014)

25. X. Zhou, J. Zhou, X. Du, Y. Wang, Journal of Hydroelectric Engineering 34, 63-72 (2014)

26. N. Arefiev. M. Mikhalev, D. Zotov, K. Zotov, N. Vatin, O. Nikonova, O. Skvortsova, S. Pavlov, T. Chashina, T. Kuchurina, V. Terleev, V. Badenko, Y. Volkova, V. Salikov, K. Strelets, M. Petrochenko, A. Rechinsky, Procedia Eng. 117, 32-38 (2015)

27. V. Badenko, V. Terleev, N. Arefiev, J. Volkova, O. Nikonova. Proceedings of the AASRI International Conference on Industrial Electronics and Applications (IEA 2015). Book Series: AER-Advances in Engineering Research. 2, 452-455 (2015)

28. V.V. Terleev, A.G. Topaj, W. Mirschel, Russ meteorol hydro+ 40, 278-285 (2015)

29. R.A. Poluektov, S.M. Fintushal, I.V. Oparina, D.V. Shatskikh, V.V. Terleev, E.T. Zakharova, Arch. Acker- Pfl. Boden. 48, 609-635 (2002)

30. R.A. Poluektov, V.V. Terleev, Russ meteorol hydro+ 11, 70-75 (2002)

31. R.A. Poluektov, I.V. Oparina, V.V. Terleev, Russ meteorol hydro+ 11, 61-67 (2003)

32. R.A. Poluektov, V.V. Terleev, Russ meteorol hydro+ 12, 73-77 (2005)

33. V.V. Terleev, W. Mirschel, U. Schindler, K.-O. Wenkel, INT AGROPHYS. 24, 381-387 (2010)

34. V. Terleev, V. Badenko, I. Guseva, W. Mirschel, AMM, 725-726, 355-360 (2015) 